\title{
Automedicación en tiempos de COVID-19. Una perspectiva desde Perú
}

\section{Self-medication in times of COVID-19. A perspective from Peru}

\author{
J. Shamir Barros-Sevillano, ${ }^{1 *}$ Carmen P. Sandoval, ${ }^{1}$ Lider S. Alcarraz-Mundial, ${ }^{1}$ y Joshuan J. Barboza ${ }^{2}$ \\ 'Universidad "César Vallejo", Facultad de Ciencias de la Salud, Escuela de Medicina, Trujillo; Universidad Señor de Sipán, Escuela de Medicina, \\ Chiclayo. Perú
}

Al 6 de setiembre de 2020, en Perú se reportaron 676848 casos confirmados de COVID-19 y 29554 fallecimientos por esta causa, cifras que identifican a la enfermedad como el principal problema de salud pública y económico del país, el cual se ubica como el quinto con más sujetos infectados en el mundo y el primero en muertes por millón de personas. ${ }^{1}$

La preocupación colectiva ha propiciado la automedicación, con una estrecha relación entre la desinformación por los medios de comunicación y una promoción desesperada del uso de medicamentos sin base científica. Actualmente, el gobierno peruano, a través del Ministerio de Salud, distribuye el "kit COVID" para el tratamiento de pacientes con enfermedad leve, equipo que incluye ivermectina, hidroxicloroquina, azitromicina y paracetamol. ${ }^{2}$ Asimismo, en diferentes regiones de Perú se elabora y distribuye magistralmente ivermectina sin registro sanitario para el tratamiento ambulatorio.

En una muestra total de 132 pacientes hospitalizados por COVID-19 en un hospital del Perú, 36 (33.9\%) ya se habían automedicado antes del ingreso. Los fármacos más frecuentes fueron los antibióticos (28.3\%), como azitromicina y amoxicilina, seguidos por ivermectina $\left(20.7 \%\right.$ ) y corticoides (17\%), ${ }^{3}$ fármacos con escasa o sin clara evidencia científica que permita aseverar que su uso temprano tiene un resultado positivo en el curso de la enfermedad ${ }^{4} y$ con los que, por el contrario, se están reportando efectos adversos.

Resulta especialmente preocupante la automedicación precoz con corticoides, los cuales solo están recomendados en pacientes hospitalizados que requieren oxigenoterapia; ${ }^{5}$ el empleo de corticoides en forma preventiva 0 al inicio de la enfermedad podría impedir al organismo contender contra el virus y agravar el cuadro de la enfermedad.

La escasez de información y el incumplimiento de la legislación sanitaria pueden seguir fomentando esta práctica. Para reducir esta tendencia, es urgente educar a la población para evitar la automedicación e informar sobre los daños colaterales que conlleva.

\section{Bibliografía}

1. World Health Organization [Internet]. Suiza: Panel de la OMS sobre la enfermedad por coronavirus (COVID-19); 2020.

2. Decreto de urgencia que dicta medidas extraordinarias para garantizar el acceso a medicamentos y dispositivos médicos para el tratamiento del coronavirus y reforzar la respuesta sanitaria en el marco del estado de emergencia sanitaria por el COVID-19. Diario Oficial Del Bicentenario El Peruano; 2020 May 20.

3. Zavala-Flores E, Salcedo-Matienzo J. Medicación prehospitalaria en pacientes hospitalizados por COVID-19 en un hospital público de Lima-Perú. Acta Med Peru. 2020;37:393-395.

4. Díaz E, Amézaga Menéndez R, Vidal Cortés $P$, Escapa MG, Suberviola B, Serrano Lázaro A, et al. Tratamiento farmacológico de la COVID-19: revisión narrativa de los Grupos de Trabajo de Enfermedades Infecciosas y Sepsis (GTEIS) y del Grupo de Trabajo de Transfusiones Hemoderivados (GTTH). Med Intensiva. 2020.

5. RECOVERY Collaborative Group, Horby P, Lim WS, Emberson JR, Mafham M, Bell JL, et al. Dexamethasone in hospitalized patients with COVID-19 - preliminary report. N Engl J Med. N Engl J Med 2021;384:693-704.

\section{Correspondencia:}

*J. Shamir Barros-Sevillano

E-mail: jbarros@ucvvirtual.edu.pe

$0016-3813 / 02020$ Academia

CC BY-NC-ND (http://creativecommons.org/licenses/by-nc-nd/4.0/).
Gac Med Mex. 2021;157:122

Disponible en PubMed

www.gacetamedicademexico.com 